Revista de Filosofía

ISSN: 0034-8244

\title{
¿Al pie de la letra? Filosofía y enciclopedismo en la España del siglo XIX: mermas y cesuras en la traducción al castellano del texto Philosophie Des Japonois de Diderot
}

\author{
Montserrat Crespín Perales ${ }^{1}$
}

Recibido: 29 de julio de 2018 / Aceptado: 10 de febrero de 2019

Resumen. En este artículo se presenta el texto de Diderot "Philosophie Des Japonois" en el que expone los rasgos del pensamiento japonés y se coteja luego con la translación de Tomás Lapeña en su Ensayo sobre la historia de la filosofía desde el principio del mundo hasta nuestros días. Del texto diderotiano se estudian las "peculiaridades" que encuentra en la filosofia japonesa. En la versión castellana, se identifican las mermas, explicándose las motivaciones tras las cesuras halladas. Se busca esclarecer el patrón moderno de transmisión y distorsión de las filosofías no-europeas.

Palabras clave: Denis Diderot (1713-1784); Tomás Lapeña (1766-1827); philosophes; ilustración; historias de la filosofía; filosofía japonesa; filosofía y enciclopedismo en la España del siglo XIX.

\section{[en] Ad pedem litterae? Philosophy and encyclopedism in nineteenth-century} Spain: losses and caesuras in the Spanish translation of Diderot's Philosophie Des Japonois

\begin{abstract}
The article introduces Diderot's "Philosophie Des Japonois" in which he exposes the traits of Japanese thought and afterwards is compared with the translation of Tomás Lapeña in his Essay on the history of philosophy from the beginning of the world to the present day. The paper studies, first, the "peculiarities" that Diderot found in Japanese philosophy. Second, reading Lapeña's Spanish version, the article identifies the losses, explaining the motivations of the caesuras found. The aim is to clarify the modern pattern of transmission and distortion of non-European philosophies.

Keywords: Denis Diderot (1713-1784); Tomás Lapeña (1766-1827); philosophes; enlightenment; histories of philosophy; japanese philosophy; philosophy and encyclopedism in nineteenth-century Spain.
\end{abstract}

Sumario: 1. Introducción; 2. Diderot, los philosophes y su desconocida mirada hacia Japón y su filosofía; 3. Diderot y la Philosophie Des Japonois: Un mundo distinto, pero igual; 4. ¿Al pie de la letra? Mermas y censura en la versión de Lapeña; 5. Consideraciones finales.

Cómo citar: Crespín Perales, M. (2020): “AAl pie de la letra? Filosofía y enciclopedismo en la España del siglo XIX: mermas y cesuras en la traducción al castellano del texto Philosophie Des Japonois de Diderot”, en Revista de Filosofía 45 (1), 47-67.

\footnotetext{
Facultad de Filosofía

Universidad de Barcelona

m.crespin@ub.edu
} 


\section{Introducción}

En el espacio dedicado a la filosofía en España durante el siglo XIX de su obra Compendio de Historia de la Filosofía (1915), el historiador de la filosofía Anselmo Herranz Establés (1864-1935) describía así el ocaso sistémico del país:

Durante el siglo XIX España ha estado en plena decadencia, lo mismo como nación que en las manifestaciones todas de su energía científica, (...); y toda nuestra filosofía, si se exceptúan tres o cuatro pensadores originales que no han conseguido formar escuela, lleva un sello extranjerizo y es mero reflejo de la de otras naciones europeas. (Herranz 2013, p. 323).

Ese sello extranjerizo queda absolutamente evidenciado si se atiende a la poca producción española de volúmenes que han servido (y sirven) como obras de referencia general en filosofía: las historias de la filosofía. Una de las pocas publicaciones que ejemplifican lo raquítico del desarrollo de este género académico, y, a su vez, lo apegado del hacer histórico-filosófico a los préstamos intelectuales de la Francia de los ilustrados, de los heterogéneos philosophes, es la obra en tres tomos del navarro Tomás Lapeña (1766-1827): Ensayo sobre la historia de la filosofia desde el principio del mundo hasta nuestros días (1806-1807) (en adelante, Ensayo).

Dado el bajo nivel de alfabetización de la población española de la época, seguro que pocos pudieron leer entonces su obra. Pero esta compilación o, en palabras de Marcelino Menéndez y Pelayo (1856-1912) en su Historia de los heterodoxos españoles (1880-1882), el fruto de este "plagiario de la Enciclopedia" (Menéndez y Pelayo 2003, p. 982), es paradigma y correa transmisora de la representación y proyección de ciertos lugares comunes al referirse a la filosofía del este asiático durante el XIX y parte del XX. Sirviéndose Lapeña del "método compilador" o arte de la "imitación selectiva", justificada por el autor con la famosa metáfora de la labor de las abejas que liban de flor en flor (Lapeña 1806, Prólogo, p. 2), traduce y transmite en castellano, las noticias, estudios y entradas de diccionarios enciclopédicos de Louis Moréri (1643-1680), o de la Encyclopédie (1751-1772) de Diderot-D’Alembert, entre muchos otros, que circulaban en la Europa ilustrada sobre la "Filosofía de los Chinos" o la "Filosofía de los Japoneses". Pero, la transmisión no es fiel, sino que está cercenada. Entre sus tareas, Lapeña se atribuye la competencia para eliminar "lo que podía contribuir a dar cierta libertad de pensar no poco perjudicial" (Lapeña 1806, Prólogo, p. 3).

Acotando este estudio al tratamiento de la filosofía japonesa, en primer lugar, se presentarán los términos precisos que emplea la entrada "Philosophie Des Japonois", escrita por Diderot en la Encyclopédie (Diderot 1765, Vol. VIII, pp. 455b-458a), ${ }^{2}$ para transmitir los rasgos y peculiaridades del pensamiento japonés en el contexto del siglo XVIII. Se reseñarán particularmente aquellos aspectos del enciclopedismo que, en ejercicio de la ilustración materialista, ubican críticamente no sólo las características que encuentran definidoras de la filosofía de Japón, sino también, las circunstancias del contacto del país con Europa y, en particular, con el cristianismo. A continuación, se cotejará el original con la translación al castellano

Con el fin de mantener la coherencia estilística y terminológica del artículo, la traducción de las entradas de Diderot de la Encyclopédie es mía. 
de Lapeña en el Ensayo, identificando los extractos eliminados o modificados para cumplir con el objetivo de hacer desaparecer lo "nocivo" de las teorías anti-religiosas ilustradas. Se finalizará con una lectura crítica de las consecuencias que se derivan de estas historias de la filosofía y cómo contribuyeron a apuntalar el entendimiento distorsionado, aún hoy, de las reflexiones genuinamente filosóficas, pero extramuros, al "canon" eurocéntrico.

\section{Diderot, los philosophes y su desconocida mirada hacia Japón y su filosofía}

En uno de sus diversos estudios sobre Denis Diderot (1713-1784), el historiador Juan Calatrava Escobar escribía con cierta amargura que Diderot no ha tenido suerte en España, ni siquiera la "suerte" de ser odiado por sus contemporáneos hispanos, ni objeto de inquina, como sí lo fueron Voltaire o Rousseau (Calatrava Escobar 1985, p. 416). Así las cosas, esa indiferencia mostrada desde España al philosophe es antecedente del desdén hacia el estudio de los escritos que dedicara el pensador a la filosofía y la religión japonesas.

Si bien es relativamente habitual encontrar el uso conceptual de la sinofilia o la sinofobia para referir a la perspectiva mantenida por los filósofos de la ilustración hacia China, menor es el empleo del par conceptual con el que entabla relaciones de familia, la "niponofilia" y la "niponofobia" que, a priori, pudiera servir como marco de estudios con análogos objetivos. Y, no obstante, la raíz de los vocablos surge en el mismo período temporal y en la cosmovisión del pensamiento europeo de los siglos XVIII y XIX. ${ }^{3}$

El desapego hacia la mucha producción que dedicaron a Japón los philosophes $\mathrm{y}$, en particular, Diderot, debería empezar a corregirse. Sería valioso sumar esfuerzos para dar a conocer, con rigor, algunos de los rasgos y peculiaridades del prisma a través del cual se acercaron al pensamiento y formas religiosas en Japón.

J.A.G Roberts, en un completo ensayo que explora precisamente esta cuestión, justifica con diversos argumentos de peso la importancia que tiene estudiar de qué modo esta generación de pensadores franceses se acercan a Japón. En primer lugar, constata que la aparición de Japón en el interior de sus intereses intelectuales se torna esencial a raíz de la proscripción del cristianismo en el país, concomitante con la política de reclusión (sakoku - 鎖国) vigente desde 1639 hasta 1853, de pleno en el período Edo también conocido como período Tokugawa (1603-1868). Aparecen entonces obras clave como la de Engelbert Kaempfer (1651-1716), The History of Japan Together with a Description of the Kingdom of Siam (La historia de Japón junto con una descripción del reino de Siam), escrita originariamente en alemán, pero publicada por primera vez en 1727 a partir de su traducción al inglés (Roberts 1989, pp. 151-152). ${ }^{4}$ El segundo factor de peso que reseña es que el interés en el estudio de China y la importancia de este país para la filosofía ilustrada se transmite

\footnotetext{
Según recoge el Centre National de Ressources Textuelles et Lexicales (CNRTL) en su portal lexicográfico, la palabra "niponofilia", que define como "partidario de Japón" (Partisan du Japon), aparece empleada, de hecho, junto a sinofilia, en uno de los ensayos del escritor François Coppée (1842-1908), Mon Franc-parler (1896). Cf., entrada "nipponophile" en el portal del CNRTL (2012).

4 El título original en alemán de la obra de Kaempfer era bien distinto al empleado en la traducción inglesa, realizada aproximadamente ochenta años después de que el autor acabara su obra: Heutiges Japan (El Japón de hoy). El, Japón, pues, del siglo XVII. Cf., Bodart Bailey (1988), p. 1.
} 
a una curiosidad intelectual análoga hacia Japón (Roberts 1989, p. 152). Aunque, se puede añadir, el archipiélago jugara un rol secundario.

Si se tilda el conocimiento que tuvieron los philosophes de uno admitido honestamente como de "segunda mano" (Roberts 1989, p. 152) o, simplemente, libresco, no es poca su preocupación por pespuntear las diferencias y las similitudes entre los dos territorios, el chino y el japonés, respecto a sus estructuras sociales y políticas y, por supuesto, filosóficas. Estos razonamientos, junto con la aportación que aquí se quiere ofrecer sobre la entrada en la Encyclopédie, "Philosophie Des Japonois", texto escrito por el mismo Diderot, deberían servir, en la línea de Roberts (1989, p. 152), para desafiar la presunción de que el conocimiento que se transmitía sobre Japón no participó - o no del mismo modo que China- en la configuración del pensamiento ilustrado del siglo XVIII. A continuación, se confirmarán o desmentirán estas primeras presuposiciones con la presentación de las bases esenciales para conocer el tratamiento que realiza el pensador sobre la filosofía japonesa.

\section{Diderot y la Philosophie Des Japonois: Un mundo distinto, pero igual ${ }^{5}$}

Diderot inicia la entrada "Philosophie Des Japonois" exponiendo la idea, habitual y, en principio, no peyorativa, de un Japón deudor del centro cultural chino. En buena lógica escéptica, se preocupa por condicionar esta idea ampliamente difundida de un Japón satélite de China al crédito que se dé a los testimonios de los portugueses. No se debe dejar a un lado el matiz del "si se debe creer" a los portugueses (Diderot 1765, Vol. VIII, p. 455b), pues cabe la posibilidad de que su testimonio no sea más que, precisamente, la transmisión de la información de un tercero que explica lo vivido y lo visto, pero al que se le puede reconocer o no la fiabilidad de lo que informa.

Japón, pues, recibe de China su filosofía, su pensamiento y estructuración política. También hereda las "supersticiones" del país del centro, algo que también subraya Diderot (1765, Vol. VIII, p. 455b) y es un lugar común en el escrutinio de los ilustrados franceses.

El concepto "superstición", ${ }^{6}$ uno de los más polisémicos y equívocos, es, de hecho, ineludible si se quiere entender el marco amplio de la exposición de Diderot. De hecho, la conceptuación de lo que caía entonces bajo la rúbrica "superstición" podría reunir en sí la llave maestra que abriera la caracterización de la época ilustrada como un tiempo en el que las diversas voces filosóficas coinciden en criticar la religión (Cassirer 2013, p. 156). Y, no obstante, si la opinión general entiende que una de las facciones en la que converge la filosofía francesa del siglo XVIII es la intención de expurgar la idea de la religión, esta misma generalización deja a un lado muchos matices. Las diversas tonalidades se proponen para, por ejemplo, no dar siempre por buena la sinonimia comúnmente aceptada entre religión y superstición. Voltaire, sin ir más lejos, las distinguirá. Como recuerda Cassirer, Voltaire:

El encabezamiento del apartado usa del juego de palabras con el que el obispo anglicano Joseph Hall (15741656) titulara su utopía distópica Mundus alter et idem (Un mundo distinto, pero igual) (1605?-1607).

Para un estudio exhaustivo del concepto y la transmisión en la España del siglo XVIII, Cf., Martínez Gil (2016). 
(...) no se cansa de repetir en sus obras y en sus cartas su vieja consigna: écrasez l'infâme y si añade cautelosamente que su lucha es contra la superstición y no contra la fe, contra la Iglesia y no contra la religión, la generación que le sigue y ve en él a su caudillo, no se detiene ya en esta distinción. (Cassirer 2013, p. 156).

Así, el neto distingo entre los dos vocablos, está claramente expuesto cuando se atiende a la definición de superstición que aporta en su Diccionario Filosófico (1764): "Casi todo lo que va más allá de la adoración de un Ser Supremo, y la sumisión del corazón a sus órdenes eternas, es superstición” (Voltaire 2005, p. 1898).

Entre la posición de Voltaire, que no se significará como ateo y mantendrá un sentido de religión dentro de sus límites (adoración al Ser supremo y sumisión a sus órdenes), y el salto cualitativo irreligioso de Diderot, hay una distancia considerable. En sus Pensamientos Filosóficos (Pensées philosophiques) (1746), Diderot describe a la superstición como el artificio del poder imaginario que produce a Dios. De hecho, le parece que, frente a la bajeza intelectual de la superstición, la fuente de la creencia del deísta, es decir, de aquel que deriva la existencia de Dios de la razón, al menos tiene más dignidad para entrar en disputa con el ateo: "XIII. Sólo el deísta puede enfrentarse al ateo. El supersticioso no está a su altura. Su dios no es más que un ser producto de su imaginación. (...)" (Diderot 2009, p. 56). Es claro que el filósofo francés no se mantendrá en los términos de la religión racional, a la que conduce el deísmo, sino que se situará, sin ambages, en el ateísmo. ${ }^{7}$ Para el filósofo, solamente abandonando la fe puede el ser humano alejarse de la pendiente que le puede hacer caer en dogmas y prejuicios para mantenerlo en condición de siervo.

Prosiguiendo con la presentación de la entrada de la enciclopedia, conviene hablar ahora del modo en el que el filósofo presenta el tensionado contacto de Japón con el cristianismo. En el relato del dramatis personae del contacto de los europeos con Japón, refulge la figura de Francisco de Jaso y Azpilicueta (1506-1552), conocido como Francisco Javier o, tras su canonización, San Francisco Javier. En palabras sardónicas de Diderot:

Francisco Javier, de la Compañía de Jesús, fue conducido allí en 1549, por un celo ardiente y hermoso, para extender la religión cristiana: predicó allí; fue escuchado; y Cristo tal vez sería adorado en toda la extensión de Japón si las gentes no hubieran sido armadas por una conducta imprudente, lo que los hizo sospechar que querían más por la pérdida de su libertad que por la salvación de sus almas. (Diderot 1765, Vol. VIII, p. 455b)

La ironía mordaz del filósofo no rebaja un ápice la verosimilitud del silogismo práctico que resume la visión política del Japón del siglo XVI y la de sus gobernantes que tuvieron claro que no compensaba perder la libertad y la soberanía por la promesa de ganar la salvación ultramundana. Ciertamente, la alusión del filósofo respecto a

Tanto Marx y Engels, como la larga historia interpretativa de la obra del primero, el marxismo, como, por supuesto, también el comunismo soviético, presentarán a Diderot como “ateo”. Así se le dibuja en el Diccionario Filosófico Marxista (1946), de Mark Moisevich Rosental (1906-1975) y Pavel Fedorovich Iudin (1899-1968): "Diderot, Dionisio (1713-1784). (...) Diderot era materialista y ateo. (...) Diderot negaba decididamente la existencia de Dios y sometió a una severa crítica los dogmas religiosos acerca de la inmortalidad del alma, el libre albedrío, \&c. Refutando la moral religiosa feudal, dio como fundamento de la conducta moral de los hombres su aspiración a la felicidad. Diderot predicaba la unión racional de los intereses personales y sociales." (Rosental, Iudin 1946, pp. 78-79). 
esas gentes armadas por una conducta imprudente señala, más que la imprudencia, la personalidad jactanciosa de dos imperios marítimos, el portugués y el español, que mantenían un constante enfrentamiento repleto de intrigas entre franciscanosespañoles y jesuitas-portugueses. Conocido es el incidente del galeón español San Felipe, confiscado por Toyotomi Hideyoshi (1537-1598) en 1596 que apuntala su convicción de prohibir y perseguir el cristianismo en tierras niponas. De acuerdo con Jurgis Elisonas:

Las cosas llegaron a un punto crítico cuando el San Felipe naufragó y Hideyoshi ordenó la confiscación del cargamento del galeón español. El piloto del barco trató de prevenir esa acción intentando impresionar a los agentes de Hideyoshi con historias sobre el poder de su amo real, el poder del imperio español y la naturaleza profunda del diseño de los españoles para la conquista mundial. Una parte indispensable de ese diseño -alegó- era una quinta columna de frailes españoles, enviadas antes que las fuerzas militares para cristianizar a la gente del país, de tal modo que la tierra pudiera ser fácilmente controlada. Ante eso, Hideyoshi "llegó a la conclusión de que los frailes de San Francisco, que habían estado en $\mathrm{Meaco}^{8}$ cerca de tres años, también deberían tomarse como espías", decidiendo eliminarlos a ellos y a sus cristianos. (...) (Elisonas 2006, p. 364)

El episodio, repleto de acusaciones entre los misioneros que quedan relatadas en los documentos que los historiadores escudriñan todavía hoy, ${ }^{9}$ se resume en la decisión drástica de Hideyoshi que ordenó la ejecución de un total de veintiséis cristianos, entre franciscanos, jesuitas y laicos japoneses. ${ }^{10}$ Más que el ejercicio de efectividad de la pena capital, la decisión supuso la proscripción rigurosa del cristianismo justificada por los hechos.

Diderot recoge este episodio sin, de nuevo, perder la ocasión e introducir su mirada fina como un bisturí. Ve con claridad que detrás de la salvación de las almas, no otra cosa se escondía sino el apego al dinero que, por arte de magia, trastoca todo, lo sagrado y lo profano:

El papel de un apóstol no sufre otro: no fue tratado [Francisco Javier] con orgullo en Japón al asociarlo con el interés y la política; las persecuciones se levantaron, los andamios se levantaron y la sangre corría por todos lados. El odio del nombre cristiano es tal en Japón que uno no lo aborda hoy sin pisar a Cristo bajo sus pies. Una ceremonia ignominiosa a la que, algunos europeos, más apegados al dinero que a su Dios, se rinden sin repugnancia. (Diderot 1765, Vol. VIII, p. 455b).

Después de fijar el relato del enfrentamiento con los imperios marítimos portugués y español en el siglo XVI y sus misioneros, Diderot prosigue elaborando la idea de

8 Kioto se conocía en Europa con el nombre de Meaco o Miyako.

9 Ejemplo de estudio prolijo en detalles y manejo de fuentes es el del historiador Emilio Sola. $C f$., Sola (1999, 2012).

10 La sentencia a muerte dará nacimiento a la larguísima historiografía, pero, también, apología, en torno a los conocidos como los Mártires de Nagasaki, que se muestra en mil y una formas. Una de ellas, no del todo conocida, es la obra de teatro que se atribuye al genio literario de Lope de Vega, aunque se pone en duda la veracidad de su autoría: Los primeros mártires de Japón (¿1617?). La pieza teatral trastoca y modifica sustancialmente los hechos. Expresa admiración por Hideyoshi como centralizador de Japón que más que precisa, resulta en una exposición del anhelo de fortalecer un imperio español que empieza ya a resquebrajarse. $C f$., Crespín Perales (2007). 
un Japón culturalmente deudor de China. Así, en la exposición con la que prosigue su texto, refiere a la mitología japonesa con cierto desdén, pues no otra cosa que fabulaciones (fables) (Diderot 1765, Vol. VIII, p. 455b) son lo que "idean" para hablar de su origen. Remitiendo al estudio de Kaempfer, apostilla la división que atribuye al alemán para periodizar la historia japonesa en fabulosa (por imaginaria), incierta y verdadera (Diderot 1765, Vol. VIII, p. 455b) Claramente, el origen del mundo, la parte del relato imaginaria es común a toda mitología porque, como indica (Diderot 1765, Vol. VIII, p. 455b), tanto chinos, como japoneses, como otros pueblos, retrotraen sus narraciones al momento previo de la creación del mundo. Esto es lo que conocemos como cosmogonía, a saber, aquellos sistemas que explican el origen y la evolución del universo.

Sin embargo, Diderot no refiere directamente a las fuentes expositivas de la cosmogonía japonesa. No menciona los textos clásicos historiográficos como el Kojiki [古事記](Crónicas de antiguos hechos del Japón) (712) o el Nihonshoki [日本書紀] (Crónicas del Japón) (720), que compilan y mezclan informaciones provenientes de la tradición oral, los mitos y algunos hechos efectivamente acaecidos en Japón. Se conforma con ubicar al lector justo en el conocido momento del surgimiento de la pareja compuesta por un dios y una diosa: Izanagi (el hombre que invita-伊邪那岐) e Izanami (la mujer que invita-伊邪那美). Esa edad de oro, ese tiempo de ventura y de creación, que el philosophe encuentra en Japón, le parece igualmente fruto de la superchería. Dice:

Ve de un polo a otro, pregunta a la gente y verás en todas partes la idolatría y la superstición establecidas por los mismos medios. En todas partes, hay hombres que se hacen respetables frente a sus semejantes, entregándose a sí mismos como dioses o como descendientes de los dioses. Encuentra gente salvaje, haz el bien, di que eres un dios y te creerán, siendo adorado durante tu vida y después de tu muerte. (Diderot 1765, Vol. VIII, p. 456a)

El patrón de medida que aplica a la mitología japonesa es el mismo con el que desdeña cualquier otro aspecto que le parezca fruto de la pura superstición que, como se dijo antes, expone como artificio del poder imaginario que produce a Dios, un ser producto y proyección de los hombres y de su afán por ser reverenciados por otros. Este es, pues, el juicio de Diderot respecto a la pareja primordial: no otra cosa que un invento, un trasunto de la estructura de poder y, sin duda, una prueba más de que los relatos religiosos supersticiosos siguen el mismo patrón en cualquier lugar del mundo. El carácter irreligioso de Diderot trufa su constante labor de costura entre las explicaciones al uso difundidas sobre la mitología japonesa. Su intención última es aleccionar al lector con esos pespuntes y, por ello, no ceja en el empeño de despertarle del ensueño de las fábulas. Porque las fábulas y la religión no son otra cosa que la adormidera de la razón.

Tras la referencia a este tiempo cosmogónico, el filósofo pasa a relatar el llamado período incierto, siguiendo a Kaempfer. Tiempo histórico, pues, no cierto o, también, inconstante, en el sentido de componerse con la mezcla de hechos fantasiosos y verídicos.

Para dibujar el cuadro de las raíces del pensamiento filosófico y religioso japonés en ese tiempo incierto, se servirá y parafraseará al historiador de la filosofía Johann Jakob Brucker (1696-1770), que en el quinto volumen de su obra Historia critica 
philosophiae a mundi incunabulis ad nostram usque aetatem deducta (1742-1767) expone muy brevemente en qué consiste la "Philosophia Iaponensium" (Brucker 1742-1744, pp. 907-919)

Diderot empieza mencionando a Fohi [Fu Xi, Fuxi] al que presenta como el primer legislador tanto de chinos como de japoneses. Al soberano mítico Fohi o Fuxi (2952 a.C), uno de los considerados en Europa como padre fundador de China y al que se atribuye la invención de los ochos trigramas de El libro de las Mutaciones (Yiying) (Cheng 2006, p. 236), lo describe a través de la iconografía con la que se representa a este padre mítico: con cuerpo de serpiente ${ }^{11} \mathrm{o}$ como cabeza sin cuerpo (o, de hecho, con un cuerpo que se asemeja a una montaña).

La centralidad que Diderot atribuye a Fohi, tanto en la raíz mitológica de China como en la japonesa es, ciertamente, como corrobora también Roberts (Roberts 1989, p. 157), una transliteración de la exposición que hace Brucker. El historiador alemán describe esa doble valencia del emperador mitológico como una de las figuras que los japoneses toman de los chinos (sinenfibus acceperunt) (Brucker 1742-1744, $\mathrm{p}$. 908). Luego, Diderot marca la jerarquía posterior de historiografía fantástica junto al surgimiento de otras figuras igual de centrales, como la de Syn-mu o Nin-O, que no es otro que el emperador Jinmu. Éste, según el sintoísmo, fundó Japón en el año 660 a.C, fecha a la que expresamente se refiere el filósofo francés y que representa con el epíteto reservado a los dioses: optimum maximus -el mejor y más grande (Diderot 1765, Vol. VIII, p. 456).

Justamente, la época del emperador Jinmu es el tiempo en el que Diderot ubica a otros dos puntales de esta historia filosófico-religiosa de Japón: Roosi [Laozi o Lao Tse] y Koosi [Confucio] (551-479 a.C). Se refiere a Roosi (Laozi) como "el niño viejo", trasladando la idea implícita en el nombre o pseudónimo que refiere al "viejo maestro" (Cheng 2006, p. 163) y, en contraste, a Confucio como el joven. En una conexión más bien confusa, procede seguidamente a introducir el otro elemento clave para definir la personalidad filosófica japonesa: el budismo (Xékia, Shaka).

De este modo, ante sus ojos, Japón no tuvo otras nociones de filosofía, moralidad y religión que no fueran aquellas procedentes del budismo, Confucio y, por tanto, como préstamo continuado de China, independientemente, se permite apuntar, de la diversidad que el tiempo haya introducido (Diderot 1765, Vol. VIII, p. 456).

Frente a otros philosophes que no mostraron el mismo interés, Diderot condena de manera singular al budismo. Como comenta Roberts, el pensador está especialmente interesado en desmontar el budismo y lo atacará de modo análogo a cualquier otra fuente de superstición y de ignorancia:

Mientras que ni Montesquieu ni Voltaire tuvieron nada específico que aportar sobre el tema del budismo japonés, (...) Una vez más, fue Diderot quien estuvo más dispuesto a condenarlo. Para él, el budismo japonés era una forma de superstición y, al atacarlo, podía hacer comentarios mordaces sobre la religión en Europa. Su comentario sobre la introducción del budismo en Japón ilustra esta actitud. Seleccionó material del estudio de Brucker e insertó sus propios comentarios irónicos. Esbozó los comienzos del budismo

11 En este caso, es habitual encontrar a la figura de Fuxi junto a la de Nügua (Nu-kua o Nüwa), la diosa madre de la mitología china. Siendo la hermana-esposa de Fuxi, aparece entrelazada a él con figura de serpiente. De Nügua se explica en algunas de las versiones sobre su trasfondo mitológico que fue la responsable de crear a los humanos de tierra y barro, siendo los surgidos del suelo amarillo, los aristócratas, y los amasados con barro, los de los órdenes inferiores. $C f$., sobre esta cuestión Leeming (2001) y Roberts (2004). 
y sugirió que la introducción de la religión había corrompido y confundido la tradición religiosa japonesa. (Roberts 1989, p. 161)

En efecto, el filósofo ataca implacablemente al budismo. Entre otras cosas, considera que introduce el germen de la corrupción de las ideas, en particular, en el racionalismo confuciano, pues planta con fuerza la enfermedad de la idolatría y el culto a las imágenes y objetos representativos de la miríada de deidades budistas. Diderot se expresa, de nuevo, con la fineza de su menosprecio:

[Se encuentran] Las mismas imposturas en Egipto, en India, en China y en Japón. Dios ha permitido este parecido entre la verdadera religión y las falsas, para que nuestra fe fuera meritoria. Hemos sido iluminados por los medios que el diablo pudo emplear para precipitar a la perdición a las naciones sobre las que Dios, con sus eternos decretos, no había resuelto poner el ojo de su misericordia.

Así, entonces, la superstición y la idolatría se escaparon de los santuarios egipcios y fueron a infectar en la distancia a la India, China y Japón, bajo el nombre de la doctrina xekiana. (Diderot 1765, Vol. VIII, p. 456b)

Describiendo a continuación que en Japón conviven otros credos y vías filosóficas y espirituales además del "dogma de Xékia", entiende que esto se debe a que la "mentira nacional es tolerante entre estas personas, pues permite que una infinidad de mentiras extranjeras subsista pacíficamente a su lado" (Diderot 1765, Vol. VIII, p. 456b). Éste es un modo de definir la tolerancia interesada. Es decir, aquella que busca la pura funcionalidad de la permisibilidad (o complicidad calculada) para conseguir mayores réditos al servicio del poder político absolutista, como se encargará de señalar más adelante.

Tras el ataque furibundo realizado al budismo como doble gemelo del cristianismo en Japón, la voz de Diderot intenta ceñirse a una postura más cercana a la neutralidad de la descripción, dando cuenta de las tres sectas (en el sentido de comunidades religiosas) que considera que conviven en el país: sintoísmo (Sintos, vieja religión), budismo (doctrina de Buda, Budso, Siaka, Xékia) y lo que presenta como el código de los filósofos morales (Sindo).

Sintetizando la exploración que hace de las tres ramas filosófico-religiosas, para empezar, sitúa al culto más antiguo del país, al sintoísmo, en la primera fase de la religiosidad: la idolatría primitiva. Ciertamente, su mirada mordaz hacia el sintoísmo que ve como una suerte de infantil religiosidad popular arcaica no busca como diana el fundamento de la religiosidad autóctona japonesa. Otra vez, el blanco de su dardo es el irracionalismo de toda religión y su vagar repetitivo sobre un patrón común que encuentra en todas las sociedades humanas. Es por ello por lo que describe la génesis del círculo vicioso del irracionalismo que se va renovando con el mismo espíritu de renacimiento de la superstición. Así es como lo indica magistralmente:

La idolatría es el primer paso del espíritu humano en la historia natural de la religión. Luego avanza al maniqueísmo y, del maniqueísmo va a la unidad de Dios, retornando a la idolatría para volver a girar en el mismo círculo. (Diderot 1765, Vol. VIII, p. 456b)

A juicio del philosophe, la historia de las religiones se inicia erigiéndose como ciencia confusa que pretende dar con el principio vital que moviliza el cosmos. Así, las 
explicaciones mitológicas muestran ese afán por fundamentar una germinal y borrosa filosofía natural y práctica en la que las fuerzas vitales se manifiestan en la infinidad de lo que es. Luego, en un vuelco que ya prefigura su idea de instrumentalización de todo espíritu de la religiosidad, las fuerzas creadoras se esquematizan para quedar en dos principios o fuerzas: el bien y el mal. Eso origina el dualismo conflictivo del bien y del mal del maniqueísmo al que refiere. La síntesis o la (aparente) solución del conflicto perpetuado entre el bien y el mal, se acaba reconduciendo en una única figura, por así decir, "conciliadora": Dios. Dios representado, sin ir más lejos, en el antropocentrismo profético de figuras de la ejemplaridad -Gautama Buda, Jesús o Mahoma. Pero el girar no cesa. Surgiendo el conflicto otra vez, como si de un paso dialéctico se tratara $\mathrm{y}$, de hecho, se puede aventurar, fruto del choque entre estos profetas ejemplares y la realidad concreta y material de sus contextos, Diderot parecería sostener que el trayecto circular vuelve a desenvolverse religiosamente en la idolatría - moderna-.

A pesar de la mordacidad con la que trata al sintoísmo, Diderot no yerra al identificar la preocupación de esta forma espiritual por fijar la felicidad presente. Por tanto, por mantener el principio de inmanencia, de una permanencia en el ahora sin que quepa la preocupación por un devenir ni trascendente ni futuro. De algún modo, el sintoísmo representa un pragmatismo eudemónico: una satisfacción y búsqueda de la felicidad hoy (Diderot 1765, Vol. VIII, p. 456b) y no en un mañana no acontecido. Ese pragmatismo y esa perspectiva "inmanentista" se truecan, no obstante, en el momento en el que el emperador se arroga su linaje emparentándose con la saga de dioses. Dice Diderot:

Tienen un pontífice que dice haber descendido en línea con los dioses que anteriormente gobernaron la nación. Estos dioses incluso tienen una reunión general en su casa el décimo mes de cada año. Él tiene derecho a instalar entre ellos a aquellos que considere dignos y se cree que no es lo suficientemente malo como para olvidar al predecesor del príncipe reinante. ${ }^{12}$ El príncipe reinante no faltará el respeto a un hombre cuyos honores divinos espera un día. Es así como el despotismo y la superstición se dan la mano. (Diderot 1765, Vol. VIII, p. 457a)

Seguidamente, con otra embestida contra el budismo, subraya otra vez la rivalidad entre el confucianismo y la filosofía india. Lo hace exponiendo el motivo del desprecio confuciano a los ídolos y cómo el budismo acaba reintroduciendo una mistificada y refinada idolatría alrededor de las estatuas de Amida Buda. ${ }^{13}$ También expone cómo el budismo, a su juicio, injerta en China el marco eidético de la inmortalidad y una idea de retribución venidera previamente inexistente. Como no podría ser de otro modo, especia la explicación alumbrando el principio de la nada budista, siempre atrayente y enigmático pero, a sus ojos, simplemente absurdo. A la luz de la clásica distinción entre doctrinas religiosas exotéricas (comunes, populares) y esotéricas (ocultas, reservadas), comenta:

\footnotetext{
Por príncipe reinante claramente se refiere al sogún.

La figura de Amida Buda representa a uno de los budas descritos en la secta budista mahāyāna de la Tierra Pura muy arraigada en el este asiático.
} 
El gran principio de la doctrina esotérica es que todo es nada y que es de la nada de lo que todo depende. De ahí la copla que un entusiasta xekiano escribió después de treinta años de meditación al pie de un árbol seco que había dibujado: “-Árbol, dime, ¿quién te plantó? -Yo cuyo principio es nada y cuyo final es nada.” (...) Estas locuras parecen muy extrañas. Mientras uno lo intenta [entender], siguiendo la sutileza de la metafísica tanto como pueda, terminará con otras locuras que no serán menos ridículas. (Diderot 1765, Vol. VIII, p. 457b)

Al tratar la tercera secta, la de los "Sendosivistas" (Sendosivistes, Sindo) o los que siguen la vía filosófica, que no es más que otra forma de referir a los confucianos, le parece que son, esencial y substancialmente, no religiosos, porque practican la virtud y la razón. $\mathrm{O}$, dicho de otro modo: son virtuosos porque siguen a la razón y la razón conviene con las acciones humanas que se mueven siguiendo la recta virtud. Asimismo, Diderot señala que, en Japón, la figura confuciana en mayor estima es la de Mencio [Moosi] (380-289 a.C). Aportando su compendio del confucianismo japonés, lo presenta en torno a cuatro principios cardinales: conformar las acciones a la virtud; ser justo con todos los hombres; ser decente y honesto moralmente; respetar las reglas de la prudencia y mantener la pureza de la conciencia y la rectitud de la voluntad (Diderot 1765, Vol. VIII, pp. 457b-458a).

Finaliza Diderot (1765, Vol. VIII, p. 458a) su exposición resaltando la figura de Ikeda Mitsumasa (1609-1682), señor del dominio de Okayama en la provincia de Bizen, ${ }^{14}$ al que presenta como príncipe de Sisen. Ikeda, figura significada por su afán por expandir la educación -para Diderot, la Ciencia y la Filosofía-, pero acosado por conspiradores, hubo finalmente de romper su lanza y renunciar a su proyecto de aumentar el conocimiento. Sean los detalles que explica el filósofo, reales, o sólo un simple embellecimiento de lo que explica Kaempfer, a Diderot lo que le importa es cerrar la entrada de la enciclopedia dedicada a la filosofía de los japoneses con una moraleja: que esta historia y el trayecto antes explicado sirvan para que aprendamos cuán altos son los obstáculos que el progreso de la razón encuentra en todas partes.

\section{4. ¿Al pie de la letra? Mermas y censura en la versión de Lapeña}

Siguiendo la estructura prevista, conviene ahora cotejar la entrada de Diderot con la translación al castellano de Tomás Lapeña en su Ensayo.

En la introducción se explicó que Lapeña defiende su método compilador o imitación selectiva de tal manera que el eufemismo esconda lo que, al leer las páginas de su obra, no es sino un simple plagio o, si se quiere rebajar la severidad, una traducción que juega expresamente con la siempre perseguida "traición" del que traslada de una lengua a otra un texto. La acción del historiador navarro conviene con la acepción común del plagiario, pues ofrece al lector una copia de lo sustancial de obras ajenas adecenadas con unas pocas adiciones estilísticas, pero, sobre todo, con selectivas mermas.

En cuanto al tratamiento que recibe el texto original de Diderot, Lapeña sustrae a los potenciales lectores de su Ensayo justamente el soplo que pudiera revivir a la muy maltrecha libertad de pensamiento en la España de inicios del siglo XIX. El

$14 C f$., la biografía que aporta de su figura Yazaki (2007). 
cotejo del texto original de Diderot junto a la transposición al castellano que hace el navarro no da lugar a equivocaciones: ha sisado toda idea, vericueto irónico o juego expresivo del filósofo francés que pudiera promover el espíritu del conocimiento, hijo del escepticismo y de la duda. Este canónigo de la "Santa Iglesia Metropolitana de Burgos" es consecuente mostrando su celo católico y cortando cualquier hilo de palabras que, al relatar la historia de la filosofía desde su génesis, pudiera contravenir la ortodoxia eclesiástica. De hecho, la cruzada contra el enciclopedismo promoverá la censura de los libros de los ilustrados al representar, como expresa en su Historia de la Filosofia (1886) otro historiador de la filosofía coetáneo, Zeferino González (1831-1894), el "furor satánico contra el cristianismo":

Este comercio intelectual entre los dos países [se refiere a Inglaterra y Francia], y la preponderancia que adquirieron en Francia las ideas religiosas, políticas y filosóficas que privaban entre las clases ilustradas de Inglaterra, preponderancia que contribuyó a la vez poderosamente a la horrible y universal corrupción de las costumbres públicas y privadas durante la Regencia y el reinado de Luis XV, explican en parte la aparición de esa nube de escritores irreligiosos, materialistas y ateos, que, poseídos de furor satánico contra el Cristianismo, organizaron conjuración inmensa y universal contra éste y contra su divino fundador Jesucristo. (González 2002, p. 418).

Así pues, es signo de coherencia, pero también, de servidumbre, que Lapeña haya eliminado en su copia literal cualquier rasgo diderotiano de carácter irreligioso.

Para empezar, el "plagiario de la enciclopedia" al que, por otro lado, es justo reconocerle la correcta traducción que realiza de la entrada, borra la referencia con la que casi inaugura Diderot su escrito y que, como se vio, sitúa al lector en el contacto de Japón con el cristianismo y la reacción enérgica de los gobernantes japoneses. Respecto a este episodio, no hay rastro de Francisco Javier como figura representativa de los misioneros, ${ }^{15}$ ni tampoco de la explicación, irónica, con la que Diderot demuestra la verdadera intención de los predicadores y representantes de los imperios marítimos portugués y español: usurpar la libertad de un pueblo a cambio de una supuesta - pero futurible e indemostrable- gloria eterna.

Del mismo modo, Lapeña elimina la enseñanza que extrae Diderot tras narrar la edad fabulosa y mítica de Izanagui e Isanami. La sustracción tiene sentido pues le servía al francés para subrayar que, a pesar de las singularidades sociales y culturales, en las gentes y en todos los lugares del mundo, se repite el mismo patrón de la mengua del libre pensamiento cuando en una comunidad humana prende la idolatría y la superstición.

Lapeña pretende, lógicamente, alejar del lector la idea de que la religión no es sino un instrumento al servicio del poder político y del régimen sustentado sobre la figura de un soberano trascendente que mantiene su autoridad, entre otras cosas, gracias a la nebulosa de la ignorancia. El pueblo, adormecido con las fábulas y supersticiones, se mostrará solícito a seguir a aquel que se presenta a sí mismo como representante o descendiente de la divinidad, sea con ropajes monoteístas o politeístas.

15 Lapeña solamente incluye una breve referencia, algo inconexa respecto al argumento previo, al final del apartado dedicado a la filosofía de los japoneses en la que recoge las descripciones de Francisco Javier sobre el número de escuelas o academias: "San Francisco Xavier en sus cartas dice, que en su tiempo había cuatro Academias en las cercanías de Meaco; que a cada una de ellas concurrían tres o cuatro mil discípulos, y que entre todas juntas no componían el número de los que asistían a la de Bandova.” (Lapeña 1806, p. 170). 
El soberano de la ciudad de Dios, de la ciudad terrena, o ambos cuando se metamorfosean en uno solo, depende directamente de presentarse bajo el aura mística y como categoría trascendente del poder. En cierto modo, mantener la crítica de Diderot a las mil formas que adopta la idolatría en las diferentes sociedades, también en la japonesa, era posibilitar que entrara la idea de que los ídolos, como iconos del poder, y, en el contexto español, el monarca, como proyección de un soberano trascendente objeto de culto, reverencia y postración, cimentaban su legitimidad en el privilegio del temor a Dios y a su séquito.

Tanto en el siglo XIX como en la actualidad, esos hombres transfigurados en descendientes de linajes divinos se presentan - de forma escrita, pictórica, escultórica, etc.- como signos semejantes a lo representado, sea del poder divino del linaje o la simbolización en la ciudad terrena de la ciudad de Dios. Si Lapeña hubiera mantenido la crítica diderotiana, directa y afilada contra la superstición y la idolatría, no otra cosa hubiera hecho que abrir la posibilidad de cuestionar la autoridad del soberano ungido. En aquel momento, de Carlos IV (1748-1819), rey del imperio español desde 1788 "por la gracia de Dios", pero que cedía gustosamente el cetro y el gobierno a la reina María Luisa de Parma (1751-1819) y a su valido, el primer ministro Manuel Godoy (1767-1851). Aquel imperio español en decadencia no solamente se mostraba temeroso de Dios y de los ilustrados, sino que temía caer en las garras de otro sujeto que se había autoproclamado emperador, Napoleón Bonaparte (1769-1821), que finalmente triunfaría e invadiría España en 1808.

En España se debía parar el viento del siglo de las revoluciones y, en particular, obstaculizar la entrada de ideas que hicieran desear en el país un vuelco del antiguo régimen siguiendo la estela de la revolucionaria Francia. Como en otros momentos de la historia, la censura se encargó de realizar esta tarea que acaba convirtiendo al país en una inmensa tierra agria en la que no se desarrolla la filosofía ilustrada ni tampoco el pensamiento filosófico-político de la modernidad, el liberalismo. Como explica Carmen Bolaños Mejías en su detallado estudio sobre la censura en la España de los siglos XVIII y XIX, se trataba de mantener el Antiguo Régimen:

Puede, pues, afirmarse que las actividades censoras resurgieron durante el reinado de Carlos IV, (...) Las noticias que venían del país vecino causaron una gran alarma en Floridablanca [primer ministro nombrado por el rey], que se dispuso inmediatamente a parar la propaganda revolucionaria, ordenando levantar una barrera profiláctica en los Pirineos y sometiendo los puertos marítimos al control más estricto, apresurándose incluso a evitar que se hablara de las cosas que acontecían en Francia. Primero se quiso parar el ingreso de folletos y obras revolucionarias en 1790; luego sucesivamente se impidió a los periódicos que publicasen cualquier noticia o comentario relativo a los asuntos de Francia, llegándose a detener cualquier posibilidad de que los embajadores foráneos recibiesen libros prohibidos, para acabar vetando la entrada de cualquier documento sedicioso. (Bolaños Mejías 2006, p. 608).

La lucha contra el enciclopedismo que se particulariza aquí en las mermas que realiza Lapeña sobre el texto de Diderot, confirma que las licencias otorgadas para publicar obras de cualquier materia, pero, en especial, de la poca producción filosófica existente en el siglo XIX en España, cumplen con la misión de aislar al país del contacto con planteamientos que pudieran poner en peligro la doctrina sobre el origen divino de la monarquía, principio al servicio del poder real absoluto (Bolaños Mejías 
2006, p. 641). Se buscaba impedir que la "conjuración sañuda contra el cristianismo" (González 2002, p. 418) triunfara o, al menos, inoculara algo del vigor que en otros lugares de Europa tenía el pensamiento ilustrado, condenado y casi erradicado de la península ibérica durante ese siglo. El miedo a la libertad de pensamiento y, por tanto, el reconocimiento de la fuerza de las ideas ilustradas se aprecia claramente al leer nuevamente a Zeferino González:

El naturalismo, el sensualismo, el materialismo y el ateísmo, constituyen el fondo de las ideas y doctrinas que contienen los escritos de estos autores, todo ello sazonado y saturado de ironía, de sátiras groseras, de odio y saña contra todo lo que lleva el nombre y la señal de Jesucristo o de su Iglesia católica. Ciencias y artes, historia y Filosofía, talento y fuerza, libertad y autoridad, todo es bueno si declara la guerra a Jesucristo; de todo echan mano para vilipendiar, combatir y extirpar la idea cristiana. (González 2002, pp. 419-420).

Así pues, Lapeña, eliminando todas las apostillas que a lo largo del texto pone Diderot para arremeter una y otra vez contra la religión -por ejemplo, eliminando la denuncia que hace del proceder circular de toda religión que presenta como la circunferencia que va de la idolatría al maniqueísmo para volver al principio idolátrico-, borra también la imagen simétrica entre budismo y cristianismo que intencionalmente proyecta el philosophe. Si se recuerda, se expusieron las constantes arremetidas del filósofo francés contra el budismo y en particular, la reducción al absurdo a la que somete a la doctrina esotérica -mistérica- sobre la nada budista. Aunque Lapeña mantiene la frase que enuncia que "El gran principio de la esotérica es, que todo es nada, y que de la nada pende todo" (Lapeña 1806, p. 168) elimina completamente la advertencia de Diderot sobre una teoría que, maquillada de sutil metafísica, no hace sino llevar a la locura y la ridiculez a todo aquel que intenta pensarla. Al abismo del irracionalismo.

Una explicación admisible para entender el motivo por el cual Lapeña elude esta reflexión de Diderot consistiría en el hecho de que, alegar que la nada budista de la que "pende todo" no es nada más que un puro sinsentido metafísico, sería, por analogía, afirmar que la creación ex nihilo lo es de igual modo. Esta intuición se puede justificar en base a otros textos del mismo pensador de entre los que se encuentran en la Encyclopédie, como la entrada "Néant, Rien, ou Négation" (Diderot 1765, Vol. XI, pp. 66b-67a). En ella, jugando constantemente con lo que Aramayo conceptúa como la metodología diderotiana, a saber, el uso dialéctico de las paradojas (Aramayo 2009 , p. 29) y manteniendo abiertas las contradicciones de ese principio que adhiere a la metafísica de los escolásticos, apela a la imposibilidad de representar o concebir la nada como "algo" -al ser re-presentada (vuelta a presentar) o concebida, esto es, formada-. Mantiene abierta la contradicción incluso si se quiere salvaguardar la inmaterialidad o "irrepresentabilidad" de esa "nada" planteándola como ente mental o conceptual (ens rationis), en correspondencia con la distinción escolástica entre ens reale ("lo que es real" -algo en el mundo) y ens rationis ("lo que es conceptual"algo en la mente). Escribe Diderot:

NINGUNO, NADA o NEGACIÓN, (Metafís.) Según los filósofos escolásticos, es una cosa que no tiene existencia real, y que se concibe y nombra solo por una negación.

Vemos gente quejándose de que después de todos los esfuerzos imaginables para concebir 
la nada, no pueden superarla. ¿Qué precedió a la creación del mundo? ¿Qué mantuvo el lugar? Nada. Pero ¿y la forma de representar esta nada? Es más fácil representar una materia eterna. Estas personas hacen esfuerzos donde no deberían, y eso es precisamente lo que los avergüenza. Quieren formar una idea que no les represente nada; pero como cada idea es real, lo que representa para ellos también es real. Cuando hablamos de la nada, para que nuestros pensamientos estén dispuestos de acuerdo con nuestro lenguaje y respondan a él, debemos abstenernos de representar cualquier cosa. Antes de la creación, Dios existió; pero lo que existía, ¿qué lugar ocupaba en el mundo? Nada; punto de lugar; el lugar ha sido hecho con el universo que es su propio lugar, porque está en sí mismo, y no fuera de uno mismo. No había nada entonces; pero ¿cómo concebirlo? No debemos concebir nada. (Diderot 1765, Vol. XI, pp. 66b-67a)

También la interpretación de Véronique Le Ru (Le Ru 2010, p. 411) apunta en el mismo sentido y puede confirmar esta conjetura interpretativa. Ella justamente señala que Diderot socava la creación ex nihilo al proponer una solución de "repuesto" de la nada que traduce como materia no creada (o eterna).

Antes de finalizar, sirva indicar en último lugar no un texto eliminado, sino una adición interesada. Diderot, en uno de los momentos en los que se esfuerza por describir con distancia neutra el budismo, las prácticas meditativas budistas y la vida en comunidad de sus fieles, estima que muestren respeto hacia las ideas de las personas con las que conviven, por diferentes o contrarias que sean entre sí. Dice:

Cualesquiera que sean sus opiniones particulares, se aman y se cultivan mutuamente. Los entendimientos, dicen, no están unidos por parentesco como los cuerpos. (Diderot 1765, Vol. VIII, p. 457b)

Resalta, pues, la valía de la tolerancia. Y, respecto a la tolerancia como virtud de la convivencia, no tiene problema el filósofo francés en afirmar que, en esto, ellos -los japoneses- valen mucho más que nosotros -los franceses-:

Debe admitirse que, si estas personas tienen cosas en las que valen menos que nosotros, también tienen cosas en las que nosotros no valemos la pena. (Diderot 1765, Vol. VIII, p. $457 b)$.

Esta frase, que le debió parecer a Lapeña que embellecía cómo los japoneses respetaban la discrepancia y las opiniones opuestas y dejaba en mal lugar a la Europa reaccionaria e intolerante, es cambiada por el navarro como sigue: "Algo racional había de haber entre tanto disparate" (Lapeña 1806, p. 168).

En consecuencia, si los japoneses se estiman entre sí y respetan las posturas de los otros, es, por concesión valorativa, lo único racional y sensato reseñable de ellos. Lo demás, lo previamente expuesto y descrito, es, a ojos de Lapeña, poco más que un disparate, algo contrario a la razón.

\section{Consideraciones finales}

En un breve texto titulado "Pequeña teoría del destino", E.M. Cioran (1911-1995) reflexiona sobre España y Rusia. Los describe como países que están obsesionados 
por sí mismos, replegados sobre sí. Incapaces de disociarse de esa preocupación por quiénes son, no pueden entregarse a la filosofía que, en su ejercicio teorético, pide distancia, la del que mira desde fuera todo y también a sí mismo. Así, le parece al pensador rumano que "El mérito de España es proponer un tipo de evolución insólita, un destino genial e inacabado.” (Cioran 2016, pp. 46-47). Parte de la evolución insólita se encuentra, claramente, en el paradójico proceso de su construcción como imperio y el crecimiento sostenido de su adherido carácter antifilosófico. El destino antifilosófico de España sobrevivirá a la pérdida de los territorios de ultramar y será una constante durante gran parte del siglo pasado.

En ese tiempo transicional, algunos paralelismos entre España y Japón son ajustados. En los siglos XVIII-XIX, el país asiático batalla por definirse a sí mismo, tratando de responder a la pérdida de una presupuesta subjetividad verdadera eclipsada, en parte, por la grandeza de China. Como explica Nishio Kanji, al hilo de su reflexión sobre la identidad japonesa:

He afirmado que no hay ningún sentido de "historia mundial" (world history) en Japón, pero los japoneses, que históricamente rivalizaron con China, han intentado trascender, de algún modo, el archipiélago japonés creando su propia visión única del orden mundial con Japón reemplazando a China como el centro del mundo civilizado. Esta visión del mundo fue válida claramente en el Período Edo. Los estudiosos de la época de Razan Hayashi ${ }^{16}$ y Soko Yamaga ${ }^{17}$ hasta los de Norinaga Motoori, ${ }^{18}$ todos vieron a Japón como el centro de la civilización, y a partir de este período surgió la convicción de que Japón era la Tierra Santa Imperecedera. (Nishio 1999)

En cuanto a la siempre deseada creatividad filosófica, la España del siglo XIX encaja con muchas de las generalizaciones que aún hoy en día se escuchan entre los legos de la historia intelectual japonesa, reconocibles a través de la jactancia del que ignora que ha caído de lleno en la falacia de comparar la producción filosófica de un continente (Europa) con un único territorio (Japón). Como dijera Piovesana (1967, p. 210), si en vez de caer en la falacia de ubicarnos en el todo olvidando interesadamente nuestra parte, nos fijáramos en las diversas naciones individualmente consideradas, hay muchos Japón en el occidente. La España decimonónica es uno de ellos: no ha sido un territorio en el que se hayan producido grandes sistemas filosóficos.

En el siglo XIX, el pensamiento filosófico en España es descrito como puramente exótico, en el sentido de mostrarse como un tapiz en el que se van incorporando formas y estilos diversos sin ocultar los retales y costuras. Como comenta Mario Méndez Bejarano (1857-1931), otro historiador de la filosofía en España en su Historia de la filosofía en España, hasta el siglo XX. Ensayo (1929):

La decadencia del pensamiento filosófico se acentúa en los ominosos días del comienzo de la agitada centuria [s.XIX] y necesidades más apremiantes que la de filosofar embargan la atención de la conciencia nacional. (...) El carácter más positivo de la filosofía española durante el siglo XIX se dibuja en el exotismo. (...) todas las direcciones filosóficas

16 Razan Hiyashi (1583-1657), filósofo neoconfuciano.

17 Sokō Yamaga (1622-1685), discípulo de Hayashi, también filósofo neoconfuciano y figura destacada como estratega militar.

18 Norinaga Motoori (1730-1801), intelectual notabilísimo y figura fundamental de la escuela conocida como “Estudios Nacionales" [kokugaku-国学]. 
extranjeras o universales hallan en nuestra patria terreno abonado para florecer, mas ni un brote puramente español se destaca en la confusa selva de tan heterogéneo ramaje. (Méndez Bejarano 2000, p. 386)

La actividad filosófica española del siglo XIX es, pues, una pura filosofía estacionaria, no necesariamente o no sólo por su carácter prestatario, sino por su falta de vitalidad y por los coadyuvantes de su anemia filosófico-científica: intromisión de la autoridad monárquica y eclesiástica en la actividad intelectual; censura, intolerancia, reaccionarismo. ${ }^{19}$

Hay otra coincidencia interesante entre Japón y España en ese esencial siglo XIX. La revolución de 1868 -la gloriosa-que abre el llamado sexenio democrático (18681874), la promulgación de la Constitución democrática (1869) y la proclamación de la Primera República en 1873, auspició un suspiro tras tanta persecución de ideas y abrió a España hacia el exterior y hacia el conocimiento:

La libertad de cátedra, tribuna y prensa, facilitó la investigación al par que aficionó a la opinión hacia los temas científicos, y ya que no logró recoger la tradición hispana, interrumpida por larga decadencia, abrió las fronteras a extraños influjos, estímulos del estudio; restableció el contacto con la cultura mundial, y nos reintegró al hogar de la mentalidad europea. (Méndez Bejarano 2000, p. 390)

En Japón, la Restauración Meiji (1868-1912) también supondría un momento crítico en la historia del país, levantando el aislamiento del archipiélago, haciendo que la filosofía europea, como disciplina asociada a la idea decimonónica de progreso, tuviera su lugar y se promoviera su móvil, la "duda metódica", tal y como enunciara Yukichi Fukuzawa (1835-1901) (Fukuzawa 2016, p. 622).

Y, sin embargo, los dos países, España y Japón, con estos senderos compartidos y con una historia que guarda más puntos de semejanza que diferencias, permanecerán, filosóficamente, dándose la espalda.

A principios del vertiginoso siglo XX, Miguel de Unamuno (1864-1936) escribiría una serie de artículos periodísticos en el diario La Nación de Buenos Aires (1907) en los que se hacía eco del creciente interés por Japón en círculos intelectuales españoles e iberoamericanos. Su actitud representa un volver las espaldas a la revigorización del gusto por lo "oriental" presente en parte de Europa en el ínterin transformativo del final del siglo XIX hacia el nuevo siglo. En aquellos años, se llenaban páginas describiendo al país del este asiático fundamentalmente a partir del género cultivado de las crónicas de viajes. Por ejemplo, en las obras del guatemalteco Enrique Gómez Carrillo (1873-1927), como en la conocida De Marsella a Tokio (1906), prologada por Rubén Darío (1867-1916) o en El alma japonesa (1907).

Unamuno, al preguntarse sobre qué era aquello que tanto fascinaba del archipiélago, llegaba a la conclusión de que la atracción por la filosofía y las religiones de Japón se debía a los ojos europeos que proyectaban lo que deseaban que les deslumbrara, no por el valor del pensamiento o las religiosidades por sí mismas (Unamuno 1972,

19 No se libra de este reaccionarismo la actividad filosófica en Cataluña. Según Méndez Bejarano, "Lograron las derechas en Cataluña un imperio que jamás soñaron en Castilla ni menos en Andalucía” (Méndez Bejarano 2000, p. 401), al relatar la suspensión de las conferencias en el Ateneu Barcelonès que impartía Pere Estasen i Cortada (1855-1913), filósofo y científico social y defensor de la corriente positivista, provocando que los intelectuales más progresistas formaran el Ateneu Lliure. 
p. 59). En sus páginas periodísticas criticará la falta de individualidad del pueblo japonés, la pobreza de poesía en el confucianismo al parecerle excesivamente sensato y lógico, o afeará al budismo que ayude a sumir en la indiferencia (Unamuno 1972, pp. 55-69). Más significativo aún es el desdén con el que se refiere a los pensadores japoneses. En "Más sobre el Japonismo", el filósofo incide en la cuestión atacando directamente a la intelligentsia japonesa. Así, en diálogo cruzado con otro intelectual de la época, Ramiro de Maeztu (1874-1936), sentenciará el bilbaíno:

(...) aquellos señores catedráticos me dejan frío, no por su falta de pasión, sino por la vulgaridad de su pensamiento. Son unos señores catedráticos tan catedráticos como los de aquí, y que, más bien que imbuidos en el budismo o en la sabiduría tradicional japonesa, me parecen empollados en la biblioteca de filosofía contemporánea que publica Alcan ${ }^{20}$ en París. Sus doctrinas me suenan a occidentales y su famoso objetivismo es el que conocemos todos por acá. (Unamuno 1972, p. 65)

La negatividad con la que describe a los filósofos de Japón es resultado, con toda seguridad, de su desconocimiento de la riqueza y pluralidad filosóficas que a finales del periodo Meiji (1868-1912) ya ha florecido entre los pioneros de la academia filosófica japonesa. En el periodo en el que escribe Unamuno, en Japón, figuras como Amane Nishi (1829-1897), Hiroyuki Katō (1836-1916), Yukichi Fukuzawa (1834-1901), Enryō Inoue (1859-1919) o Tetsujirō Inoue (1855-1944) ya habían puesto las bases para que el suelo fértil de la reflexión diera frutos que traspasarían las fronteras del territorio japonés, con obras ineludibles para entender el legado vivo del pensamiento filosófico contemporáneo, como las de, entre muchos otros, el más influyente pensador del siglo pasado, Kitarō Nishida (1870-1945), del que en el año 1963, Revista de Occidente publicaría la traducción al castellano de su, aún hoy en día, obra más difundida y conocida, Ensayo sobre el Bien (1911) (Nishida 1963). Los traductores fueron los jesuitas Anselmo Mataix (1928-2012) y José María de Vera (1928-2019), vinculados ambos a la Universidad de Sofía, en Tokio, que, a su vez, difundirían en las aulas de este centro universitario privado de la Compañía de Jesús, la filosofía española contemporánea. Mataix, por ejemplo, introduciría el interés por la obra de Unamuno (Sumita 2009, p. 124).

$\mathrm{Y}$, con todo, en nuestro contexto cercano, sigue en gran parte vigente este entendimiento distorsionado sobre el legado filosófico de Japón, su mitología, la confluencia de sintoísmo, confucianismo y budismo o la conceptuación sobre la nada budista, que funciona como imán y fetiche en muchos estudios filosóficos sobre Japón, al lado de su par, la vacuidad.

Evidentemente, leer hoy a Diderot y a su plagiario, Lapeña, es, como poco, extraño. Es un ejercicio de arqueología. Se escudriña la filosofía y el proceso de transmisión de lo que, de segunda y tercera mano, se difundía sobre la filosofía de los japoneses, a través de sus restos o de objetos de anticuario, como lo es el Ensayo y, en menor medida, la Encyclopédie, que, confirmando las sospechas de Diderot, le regalaría con el pasar de los años, la posteridad, que creía que era para el filósofo

20 Se refiere a la editorial dirigida por Felix Mardochée Alcan (1841-1925) que, entre su fondo editorial de manuales para los liceos franceses, publicará la colección Bibliotèque de Philosophie Contemporaine, en el que, por ejemplo, se podrán leer voces intelectuales que, de hecho, históricamente serán muy importantes para la modernidad y contemporaneidad filosóficas en Japón como Herbert Spencer (1820-1903), Wilhelm M. Wundt (1832-1920) o Henri Bergson (1859-1941), entre otros. 
como el otro mundo para el hombre religioso (Diderot 2009, p. 16).

Esta tarea que ha desenterrado a estos fantasmas de la ilustración y la contrailustración, puede servir para identificar algunos indicadores hegemónicos de la filosofía que perviven incluso detrás de ejercicios de crítica del eurocentrismo o del orientalismo que, en el fondo, no consigue ni negar ni superar. Asimismo, seguir las huellas de una personalidad filosófica tan imponente como la de Diderot, atender a las bases de su materialismo y a su crítica religiosa, debería servir para reconocer los peligros que se esconden en las teologías difusas contemporáneas, sincréticas por puro oportunismo ideológico. Un rasgo característico de la "teología con hábitos seculares" (Blom 2018, p. 24) y de los actuales tecno-teólogos es que encuentran, en su impostado alegato por la filosofía del este asiático, la lámpara que deslumbra e impide apreciar que su verdadera intención no es otra que renovar el irracionalismo y el culto a inventadas tradiciones mistéricas, "astillas de sabiduría" para llegar a la "verdad primigenia" (Eco 1995) o a la plena conciencia. Para arribar, al final, al mismo sitio filosóficamente vacío del que parten: no, nada.

\section{Referencias Bibliográficas}

Aramayo, R.R. (2009): "Diderot, o el apogeo del filosofar", en Diderot, Pensamientos filosóficos. El combate por la libertad, Barcelona, Editorial Proteus, pp. 13-41.

Bodart Bailey, B.M. (1988): "Kaempfer Restor'd”, Monumenta Nipponica, Vol. 43, N. 1, pp. 1-33. DOI: $10.2307 / 2384515$

Bolaños Mejías, M.C. (2006): "Censura Inquisitorial, Ilustración y Liberalismo una aproximación jurídico política”, Anuario de historia del derecho español, 76, pp. 605644. En línea en: https://dialnet.unirioja.es/servlet/articulo?codigo=2286166 (último acceso julio 2018)

Blom, P. (2018): Gente peligrosa. El radicalismo olvidado de la Ilustración europea, Barcelona, Editorial Anagrama.

Brucker, J.J (1742-1744): “Liber Tertius. De Philosophia Exotica. Caput Quartum. De Philosophia Iaponensium", en Historia critica philosophiae, a mundi incunabulis ad nostram usque aetatem deducta. Tom. 4-2, Lipsiae, Bern, Christoph Breitkopf, pp. 907919. En línea en: https://babel.hathitrust.org/cgi/pt?id=uc1.31378008235023;view=1up;s eq=11 (último acceso julio 2018)

Calatrava Escobar, J.A. (1985): "Diderot en España: una revisión crítica”, Azafea, 1, pp. 415-421. En línea en: https://gredos.usal.es/jspui/bitstream/10366/68786/1/Diderot_en_ Espana_una_revision_critica.pdf (último acceso julio 2018)

Cassirer, E. (2013): Filosofía de la Ilustración, México D.F., Fondo de Cultura Económica.

Cheng, A. (2006): Historia del pensamiento chino, Barcelona, Edicions Bellaterra.

Cioran, E.M. (2016): Adiós a la filosofía, Madrid, Alianza Editorial.

Centre National de Ressources Textuelles et Lexicales (CNRTL) (2012): "Nipponophile, adj.", Nancy Cedex, CNRTL. En línea en: http://www.cnrtl.fr/definition/nipponophile (último acceso marzo 2018).

Crespín Perales, M. (2007): “Lope de Vega y Japón”, Boletín de estudios de filosofía y cultura Manuel Mindán, 3, pp. 86-103.

Diderot, D. (1765): "Philosophie des Japonois, (Hist. de la Philosophie.)", en D. Diderot, J. D'Alembert (Eds.), Encyclopédie ou Dictionnaire raisonné des sciences, des arts et des métiers (1751-1772), Vol. VIII, pp. 455b-458a, en Édition Numérique Collaborative et 
Critique de l'Encyclopédie (ENCCRE). En línea en: http://enccre.academie-sciences.fr/ encyclopedie/ (último acceso julio 2018)

Diderot, D. (1765): "Néant, Rien, ou Négation, (Métaphys.)", en D. Diderot, J. D’Alembert (Eds.), Encyclopédie ou Dictionnaire raisonné des sciences, des arts et des métiers (1751-1772), Vol. XI, pp. 66b-67a, en Édition Numérique Collaborative et Critique de l'Encyclopédie (ENCCRE). En línea en: http://enccre.academie-sciences.fr/encyclopedie/ (último acceso julio 2018)

Diderot, D. (2009): Pensamientos filosóficos. El combate por la libertad, Barcelona, Editorial Proteus.

Eco, U. (1995): “Ur-Fascism”, The New York Review of Books, June 22, 1995 Issue. En línea en: https://www.nybooks.com/articles/1995/06/22/ur-fascism/ (último acceso julio 2018)

Elisonas, J. (2006): "Christianity and the daimyo", en J. Whitney Hall, J.L. McClain, (Eds.), The Cambridge History of Japan. Volume 4: Early Modern Japan, 6th printing, Cambridge, Cambridge University Press, pp. 301-372.

Fukuzawa, Y. (2016): "En alabanza de la duda metódica”, en J.W. Heisig, T.P. Kasulis, J.C. Maraldo, R. Bouso García (Eds.), La filosofía japonesa en sus textos, Barcelona, Herder, pp. 621-624.

González, Z. (2002): Historia de la Filosofía, Tomo Tercero, Madrid, Agustín Jubera. En línea en: http://www.filosofia.org/zgo/hf2/index.htm (último acceso julio 2018)

Herranz Establés, A. (2013): Compendio de Historia de la Filosofía, Barcelona, Luis Gili. En línea en: http://www.filosofia.org/aut/002/ahchf220.htm (último acceso julio 2018).

Lapeña, T. (1806): Ensayo sobre la historia de la filosofía desde el principio del mundo hasta nuestros dias, Tomo I, Burgos, Imprenta de D. Ramón de Villanueva. En línea en:

https://archive.org/details/ensayosobrelahis01lapguat (último acceso julio 2018)

Leeming, D.A. (2001): A dictionary of Asian mythology, Oxford, Oxford University Press. En línea en: http://www.oxfordreference.com/view/10.1093/oi/ authority.20110803100241815 (último acceso junio 2018)

Le Ru, V. (2010): "Diderot”, en J. Laurent, C. Romano (Eds.), Le Néant: Contribution à l'histoire du non-être dans la philosophie occidentale, Paris, Presses Universitaires de France, pp. 405-411.

Martínez Gil, F. (2016): "Religión o superstición. Un debate ilustrado en la España del siglo XVIII”, Hispania Sacra, LXVIII, 137, pp. 327-342. DOI: https://doi.org/10.3989/ hs. 2016.022

Méndez Bejarano, M. (2000): Historia de la filosofía en España, hasta el siglo XX. Ensayo, Madrid, Renacimiento. En línea en: http://www.filosofia.org/aut/mmb/index.htm (último acceso julio 2018)

Menéndez y Pelayo, M. (2003): Historia de los heterodoxos españoles, Alicante, Biblioteca Virtual Miguel de Cervantes.

Nishida, K. (1963): Ensayo sobre el Bien, Madrid, Revista de Occidente.

Nishio, K. (1999): “Japan's Identity: Is Asia One? Is Japan Part of the East?”, en K. Ito, K. Nishio, S. Kitaoka (Eds.), Japan's identity. Neither the West Nor the East, Tokyo, The Japan Forum on International Relations(JFIR). En línea en: https:/www.jfir.or.jp/e/ special_study/seminar1/conversation.htm (último acceso julio 2018)

Piovesana, G.K. (1967): Pensamiento Japonés Contemporáneo, Madrid, Razón y Fe.

Sola, E. (1999, 2012): Historia de un desencuentro. España y Japón (1580-1614), Madrid, E-Libros - Historia de un desencuentro. En línea en: http://www.archivodelafrontera. com/e-libros/historia-de-un-desencuentro-espana-y-japon-en-el-siglo-de-oro/ (último acceso mayo 2018) 
Roberts, J. (2004): Chinese Mythology A to Z, New York, Facts on File.

Roberts, J.A.G. (1989): "Not the Least Deserving. The Philosophes and the Religions of Japan", Monumenta Nipponica, Vol. 44, N. 2, pp. 151-169. DOI: 10.2307/2384966

Rosental, M.M., Iudin, P.F. (1946): Diccionario Filosófico Marxista, Montevideo, Ediciones Pueblos Unidos.

Sumita, T. (2009): “Entrada y difusión de la filosofía unamuniana en Japón”, en A. Chaguaceda Toledano (Ed.), Miguel de Unamuno. Estudios sobre su obra. IV, Salamanca, Ediciones Universidad de Salamanca, pp. 101-126.

Unamuno, M. (1972): “El problema religioso en el Japón” y “Más sobre el japonismo”, en Libros y autores españoles contemporáneos, Madrid, Espasa Calpe.

Voltaire (2005): Dictionnaire philosophique, Mazères, Le chasseur abstrait. En línea en: http:// www.lechasseurabstrait.com/revue/IMG/pdf/Voltaire_-_Dictionnaire_philosophique.pdf (último acceso julio 2018)

Yazaki, H. (2007): "Ikeda Mitsumasa (1609-82)", en VV. AA, Encyclopedia of Shinto, Tokyo, Kokugakuin University. En línea en: http://k-amc.kokugakuin.ac.jp/DM/detail. do?class_name $=$ col_eos\&data_id=22652 (último acceso junio 2018). 